\title{
Application of new high-performance liquid chromatography and solid-phase extraction materials to the analysis of pesticides in human urine
}

\author{
Joseane M. Pozzebon ${ }^{\mathrm{a}}$, Sonia C.N. Queiroz ${ }^{\mathrm{b}}$, Lúcio F.C. Melo ${ }^{\mathrm{a}}$, Marcos A. Kapor ${ }^{\mathrm{a}}$, \\ Isabel C.S.F. Jardim ${ }^{\mathrm{a}, *}$ \\ ${ }^{a}$ Department of Analytical Chemistry, Chemistry Institute, State University of Campinas, P.O. Box 6154, 13084-971, \\ Campinas, SP, Brazil \\ ${ }^{\mathrm{b}}$ Embrapa Environment, P.O. Box 69, 13820-000, Jaguariúna, SP, Brazil
}

\begin{abstract}
A method for the simultaneous determination of diuron and linuron pesticides in human urine was developed, using both solid-phase extraction (SPE) and high-performance liquid chromatography (HPLC) phases made in our own laboratory. These materials were prepared by sorption of polysiloxanes onto a silica surface, followed by immobilization. The HPLC columns were prepared from poly(methyloctylsiloxane), PMOS, immobilized onto silica with microwave radiation while the SPE cartridges where made with poly(methyloctadecylsiloxane), immobilized thermally. Method validation was performed for diuron and linuron for three fortification levels. The recoveries obtained were $85-103 \%$, the inter- and intra-assay precisions were less than 1.6 and $1.8 \%$, respectively. The limits of quantitation and detection for diuron were 2.4 and 8.0 $\mu \mathrm{g} / 1$ and for linuron were 5.0 and $12 \mu \mathrm{g} / 1$, respectively.
\end{abstract}

(C) 2002 Elsevier Science B.V. All rights reserved.

Keywords: Stationary phases, LC; Sorbents; Pesticides; Siloxanes

\section{Introduction}

Exposure to pesticides is a concern of the general population, especially for residents in contaminated sites. Public health officials are frequently asked to evaluate an individual's risk of developing health problems from possible exposure to pesticides in the environment. Although most people are not occupationally exposed to pesticides, nearly everyone has some level of exposure resulting from food, air, water, or dermal contact [1,2]. Thus, fast, easy,

\footnotetext{
*Corresponding author. Tel.: +55-19-3788-3061; fax: +55-193788-3023.

E-mail address: icsfj@iqm.unicamp.br (I.C.S.F. Jardim).
}

effective and validated methods for determination of pesticides in biological fluids are more necessary each year to monitor pesticides in the human body.

Urine, a very complex and multicomponent mixture, is one of the biological fluids of most interest. Large numbers of compounds ingested or formed in the body by metabolism are excreted in urine. Several classes of pesticides are metabolized or degraded to ureas or anilines [3-5]. The analysis of ureas in urine can thus provide an index of exposure to many of the pesticides in the environment.

Selective isolation of the analytes from the samples using a preconcentration procedure is often necessary prior to separation and measurement [6]. Many methods described in the literature for the 
determination of ureas and their metabolites (anilines) in urine require derivatization, silica gel clean-up and gas chromatography [5,7]. Recently, the use of high-performance liquid chromatography (HPLC) in this type of analysis has been developed, making possible the determination of new classes of pesticides. However, the use of solid-phase extraction (SPE) has not been reported in the literature for determination of neutral pesticides in urine by HPLC.

New materials for use as HPLC stationary phases and as SPE sorbents have been developed in recent years. These new materials consist of polysiloxanes sorbed and immobilized onto an appropriate silica support. This promising alternative method, instead of a chemical reaction, uses a wide variety of immobilization techniques and has been successfully applied to prepare several HPLC stationary phases, such as poly(methyloctylsiloxane) (PMOS) on zirconized silica $[8,9]$, titanium-grafted silica [10] and pure silica [11-15]. A SPE sorbent based on poly(methyloctadecylsiloxane) (PMODS) immobilized by $\gamma$-radiation onto silica has also been described [16]. The main advantages of these procedures are good performance, lower cost, simplicity and reduction of toxic residues.

Another method for polymer immobilization is microwave radiation. This immobilization procedure has been used to prepare the stationary phase for HPLC columns, using PMOS and silica. Microwave radiation is a type of nonionizing energy that causes molecular movement from the phenomena of ionic migration and dipolar rotation [17-19]. The main advantage of the use of microwave irradiation is the high-speed heating, since it can accomplish a thermal immobilization more rapidly than oven heating. In addition, the cost and the precautions are minimized if compared with $\gamma$ radiation and several other immobilization methods.

Validation is one of the most important steps in method development for analytical determinations. The main parameters involved are precision (intraand inter-assay), recovery, limit of detection (LOD), limit of quantitation (LOQ) and linearity [20].

This paper describes the validation of a method using SPE and HPLC for determination and quantification of the pesticides diuron and linuron (substituted ureas) in human urine. Both the HPLC and SPE materials were prepared in our laboratory by immobilization of polysiloxanes onto a silica surface.

\section{Experimental}

\subsection{Chemicals and materials}

Diuron and linuron standards were obtained from DuPont and Hoescht, respectively. Stock solutions of each herbicide were prepared in methanol at concentrations of $100.9 \mu \mathrm{g} / \mathrm{ml}$ (diuron) and $102.8 \mu \mathrm{g} /$ $\mathrm{ml}$ (linuron). The solutions used to construct the calibration curves and to spike the samples were prepared in mobile phase at a concentration of 2000 $\mu \mathrm{g} / \mathrm{l}$ for each herbicide and stored in the refrigerator at $4{ }^{\circ} \mathrm{C}$.

The calibration curves involved eight different concentrations: $20,40,80,160,320,600,800$ and $1000 \mu \mathrm{g} / 1$ for diuron and 30,60, 120, 240, 500, 800, 1200 and $1500 \mu \mathrm{g} / \mathrm{l}$ for linuron. The injections were made in three replicates.

Acetonitrile and dichloromethane were Mallinckrodt chromatographic grade. Other reagents and solvents were analytical grade. Purified water was obtained from a Millipore Milli-Q Plus system. The following solvents were used in the preparation of the SPE sorbents: $n$-hexane (Mallinckrodt, HPLCgrade), methanol (Mallinckrodt, HPLC-grade) and $n$-pentane (Merck, analytical-reagent grade).

The silica for SPE was from Fluka, irregular particles, (0.040-0.063 mm, 200-400 mesh), pore size $10 \mathrm{~nm}$ and for the HPLC stationary phases it was from Phase Separations (Spherisorb $5 \mu \mathrm{m}$ spherical particles, $8.0 \mathrm{~nm}$ pore size, $186 \mathrm{~m}^{2} / \mathrm{g}$ specific surface area). PMODS and PMOS were from Petrarch Silanes and Silicones.

\subsection{Equipment}

The HPLC system consisted of a Rheodyne 7725i injector with a $10-\mu l$ loop, a Waters 510 pump and a Waters UV-Vis absorbance detector (Model 486). The data acquisition and treatment were performed by CHROMPERFECT software, version 3.03. The mobile phase (acetonitrile-water, 40:60, v/v) flow-rate was set at $0.8 \mathrm{ml} / \mathrm{min}$ and UV detection was at $254 \mathrm{~nm}$. 
All measurements were carried out at room temperature.

The urine samples were centrifuged in an Excelsa centrifuge, model MP, from Fanem (São Paulo, Brazil). The stationary phases were irradiated in a CCE M-34 microwave oven or heated in a ME27F model oven from Electrolux.

A model 51769 Haskel pump was used to pack the internally polished [21] HPLC columns.

\subsection{Urine collection and storage}

Urine samples (blanks) from human volunteers were collected and kept frozen at $-20{ }^{\circ} \mathrm{C}$ until use. After the urine samples had been thawed, they were shaken for homogenization. The required volume was then sampled as quickly as possible to avoid sedimentation of any solids.

\subsection{Preparation of SPE cartridges}

The silica support was dried at $120{ }^{\circ} \mathrm{C}$ for $24 \mathrm{~h}$. A sufficient quantity of support was added to a solution of PMODS dissolved in $n$-pentane to give a material with $40 \%(\mathrm{w} / \mathrm{w})$ of PMODS. The mixture was stirred gently for $3 \mathrm{~h}$ at room temperature, after which the solvent was evaporated slowly at room temperature.

For thermal immobilization, an amount of the $\mathrm{C}_{18}$ loaded support was placed in a $120^{\circ} \mathrm{C}$ oven for $4 \mathrm{~h}$, at atmospheric pressure. After immobilization the material was placed in a stainless steel tube. This tube was connected to a Waters 510 pump for extraction of all remaining soluble PMODS by passing approximately $25 \mathrm{ml}$ of $n$-hexane per gram of sorbent, at a flow-rate of $2 \mathrm{ml} / \mathrm{min}$. Then, $15 \mathrm{ml}$ of methanol for each gram of material was passed through the tube, at a flow-rate of $3 \mathrm{ml} / \mathrm{min}$. To make sure that all soluble residues were removed, an extra extraction step was made using a high-pressure packing pump (Haskel), at 1000 p.s.i. (6.9 MPa), in a proportion of $20 \mathrm{ml}$ of methanol per gram of sorbent. After extraction, the solid-phase was removed from the tube and was kept at room temperature for $48 \mathrm{~h}$ for the solvent evaporation.

The cartridges were prepared using $0.5 \mathrm{~g}$ of sorbent packed in a 5-ml polypropylene syringe. The material was retained by two polyethylene frits (20 $\mu \mathrm{m}$ pore size).

\subsection{Preparation of the HPLC stationary phase}

A sufficient quantity of silica was added to a solution of PMOS dissolved in dichloromethane to give a material with $40 \%(\mathrm{w} / \mathrm{w})$ of PMOS. This mixture was stirred for $3 \mathrm{~h}$ before slow evaporation of the solvent at room temperature. The stationary phases were irradiated in a microwave oven at 495 $\mathrm{W}$ for $900 \mathrm{~s}$ and then extracted with chloroform and methanol at a pressure of $34.5 \mathrm{MPa}$ to eliminate excess polymer. Columns were downward packed at 34.5 MPa in a Haskel pump using a $10 \%$ (w/v) slurry of the packing material in chloroform with methanol as propulsion solvent.

\subsection{Sample preparation}

A 2-ml volume of urine was fortified by addition of a predetermined volume of the $1000 \mu \mathrm{g} / \mathrm{l}$ of solution containing the herbicides, resulting in three levels of fortification, 40, 80 and $160 \mu \mathrm{g} / \mathrm{l}$ for diuron, and 60, 120 and $240 \mu \mathrm{g} / 1$ for linuron. The sample was basified by addition of $200 \mu$ l of $\mathrm{NH}_{4} \mathrm{OH}(\mathrm{pH} \sim 9)$ and diluted with $4 \mathrm{ml}$ of acetonitrile. Deproteinization was carried out by centrifugation ( $5 \mathrm{~min}, 3000 \mathrm{~g}$ ). A 3-ml aliquot of the supernatant containing urine-acetonitrile $(1: 2, \mathrm{v} / \mathrm{v})$ was separated and diluted with $20 \mathrm{ml}$ of Milli-Q water for the extraction procedure.

The sample was percolated through the SPE cartridges under vacuum at a flow-rate of $3 \mathrm{ml} / \mathrm{min}$. Before sample application, the SPE cartridges were conditioned with $10 \mathrm{ml}$ of methanol and equilibrated with $5 \mathrm{ml}$ of Milli-Q water. After the sample had passed through the cartridge by vacuum, the cartridge was washed with $5 \mathrm{ml}$ of Milli-Q water. This eluate was discarded and the sorbent bed was dried under vacuum for $3 \mathrm{~min}$. The analytes were then eluted with $3 \mathrm{ml}$ of dichloromethane. The solvent was evaporated to dryness under a stream of nitrogen and the residue was dissolved in $200 \mu \mathrm{l}$ of acetonitrile. The injection volume was $10 \mu l$. 


\subsection{Method validation}

The LOD is the lowest pesticide concentration that can be detected but not necessarily quantified in a sample [22]. The LOD is expressed as a concentration in terms of signal-to-noise ratio $(S / N)$. In this study LOD was calculated using three times the noise level.

The LOQ is the lowest pesticide concentration which can be determined or quantified in a sample with acceptable precision under the stated operational conditions of the method [23]. A $S / N$ ratio of ten times the noise level was used to determine the LOQ.

After defining the analytical conditions, tests were made on the recovery of herbicides after SPE and HPLC. The recovery was measured as the response after processing a matrix matched standard, expressed as a percentage of the response of a pure standard which has not been subjected to sample pretreatment. It indicates whether the method provides a response for the entire amount of analyte that is present in the sample. It is best established by comparing the replicate responses of extracted samples at matrix concentrations with those of nonextracted standards which represent $100 \%$ recovery. The recovery was calculated [24] using the equation:

Recovery $=\frac{\text { mass of analyte after extraction }}{\text { mass of analyte added }} \times 100$

The linearity of a method is a measure of range within which the results are directly, or by a well defined mathematical transformation, proportional to the concentration of analyte in a sample. For this analytical chromatographic technique, a linear relationship is observed between the detector response (y) and concentration $(x)$ of the analyte in the samples in the form of linear calibration curve obtained by least-squares linear regression procedures [25] $y=a+b x$ where $a$ is the intercept of the calibration curve and $b$ is the slope.

The precision determines the analytical deviation, and is the most important criteria for evaluating analytical method performance. Precision reflects the variation in results when repetitive analysis are made on the same sample. The intra-assay precision was determined on the same day and consisted of three series and three replicates at each of three concentration levels. Inter-assay precision was calculated in three series and three replicates at one concentration on three different days.

The numerical value used was the relative standard deviation (RSD) of triplicate measurements of the analytes, using the equation:

$\mathrm{RSD}=100 s / x_{\mathrm{m}}$

where $s=\left[\sum\left(x_{\mathrm{i}}-x_{\mathrm{m}}\right)^{2} / n-1\right]^{1 / 2}, x_{\mathrm{m}}=\sum x_{\mathrm{i}} / n, n$ is the total number of measurements, and $x_{\mathrm{i}}$ is number of the individual measurements.

\section{Results and discussion}

\subsection{SPE cartridges}

Table 1 shows the results of characterization tests

Table 1

Characteristics of some commercially available $\mathrm{C}_{18}$ sorbents and the sorbents obtained by thermal immobilization of PMODS onto silica

\begin{tabular}{|c|c|c|c|c|c|c|}
\hline $\begin{array}{l}\text { Commercial } \\
\text { name }\end{array}$ & Company & $\begin{array}{l}\text { Type of } \\
\text { bonding }\end{array}$ & $\% \mathrm{C}$ & $\begin{array}{l}\text { End- } \\
\text { capped }\end{array}$ & $\begin{array}{l}\text { Pore size } \\
(\mathrm{nm})\end{array}$ & $\begin{array}{l}\text { Particle size } \\
(\mu \mathrm{m})\end{array}$ \\
\hline Supelclean LC-18 & Supelco & $\begin{array}{l}-\mathrm{Si}\left(\mathrm{CH}_{3}\right)_{2} \mathrm{C}_{18} \mathrm{H}_{37} \\
\text { (monofunctional silane) }\end{array}$ & 10 & Yes & 6 & $40-45$ \\
\hline Bond Elut & Varian & $\begin{array}{l}-\mathrm{SiC}_{18} \mathrm{H}_{37} \\
\text { (trifunctional silane) }\end{array}$ & 17 & Yes & 6 & $40-120$ \\
\hline Sep-Pak $\mathrm{C}_{18}$ & Waters & $\begin{array}{l}-\mathrm{Si}\left(\mathrm{CH}_{3}\right)_{2} \mathrm{C}_{18} \mathrm{H}_{37} \\
\text { (monofunctional silane) }\end{array}$ & 12 & Yes & 13 & $55-105$ \\
\hline Sep-Pak $† \mathrm{C}_{18}$ & Waters & $\begin{array}{l}-\mathrm{SiC}_{18} \mathrm{H}_{37} \\
\text { (trifunctional silane) }\end{array}$ & 17 & Yes & 13 & $37-55$ \\
\hline \multicolumn{7}{|c|}{ Sorbent from this work } \\
\hline \multicolumn{3}{|c|}{$\mathrm{C}_{18}$ (thermally immobilized and extracted) } & 15 & No & 10 & $40-63$ \\
\hline
\end{tabular}


Table 2

Effect of microwave immobilization (495 W, $900 \mathrm{~s}$ ) on PMOS sorbed on 5- $\mu$ m Spherisorb silica

\begin{tabular}{llllr}
\hline Stationary phase & $\begin{array}{l}N / \mathrm{m}^{\mathrm{a}} \\
\text { (plates/meter) }\end{array}$ & $A_{\mathrm{s}}{ }^{\mathrm{a}}$ & $k^{\mathrm{a}}$ & $R_{\mathrm{s}}{ }^{\mathrm{b}}$ \\
\hline Without microwave treatment & 44100 & 2.3 & 3.5 & 2.2 \\
With microwave treatment & 94500 & 1.5 & 2.9 & 2.9 \\
\hline
\end{tabular}

${ }^{\mathrm{a}}$ Calculated for the naphthalene peak.

${ }^{\mathrm{b}}$ Calculated for the toluene-naphthalene pair.

of the solid-phase obtained after thermal immobilization of polymer and after extraction of the excess polymer. These results are compared with some commercial sorbents. For commercial sorbents, the
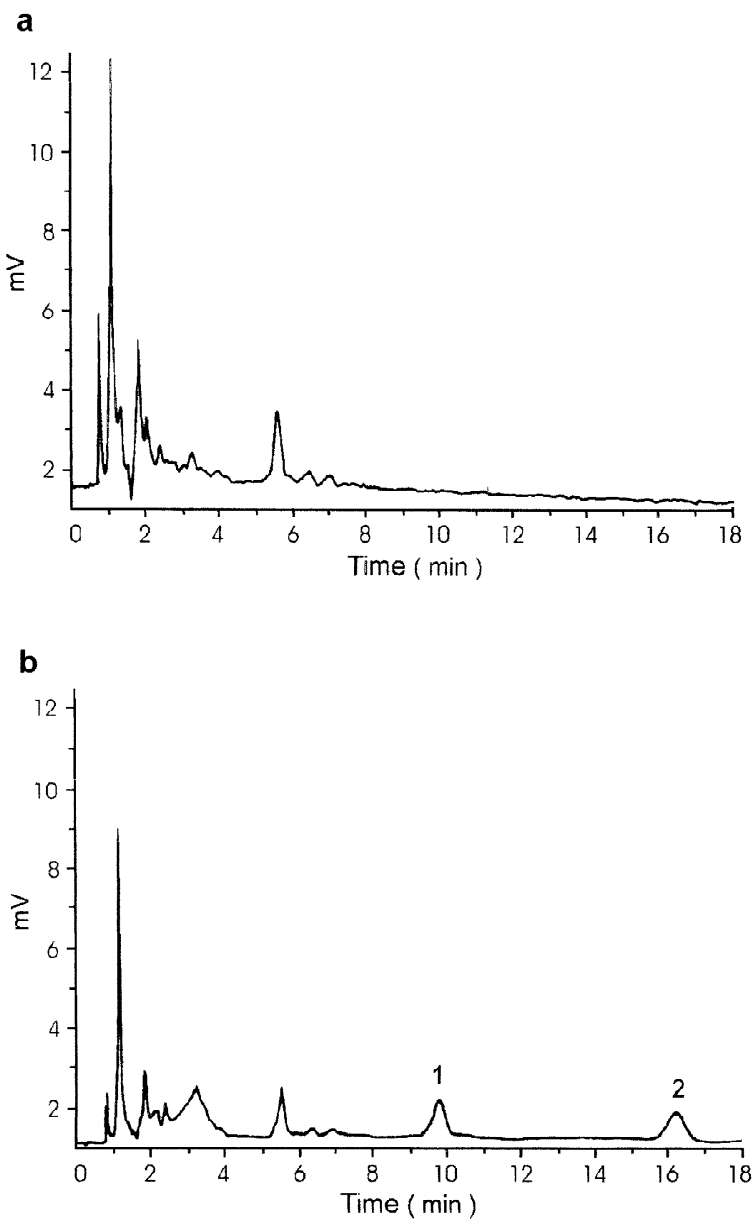

Fig. 1. Chromatograms: (a) blank urine, (b) urine spiked with pesticides. Stationary phase: laboratory-made poly(methyloctylsiloxane), microwave-immobilized on $5-\mu \mathrm{m}$ silica; mobile phase $\mathrm{MeCN}$-water (40:60, v/v); flow-rate $0.8 \mathrm{ml} / \mathrm{min}$; detection $\mathrm{UV}$ at $254 \mathrm{~nm}$; injection volume $10 \mu \mathrm{l}$. Elution order: (1) diuron, (2) linuron.
$\% \mathrm{C}$ ranged from 10 to $17 \%$ and for the sorbent obtained in this work the value was $15 \%$. Thus, the proposed method to obtain PMODS-loaded silica, immobilizated by thermal treatment, produces a material with similar features to commercial sorbents, especially with respect to the $\% \mathrm{C}$, with the advantage of being a much easier, cheaper, less time consuming synthesis process, which uses less toxic solvent than the traditional chemical reaction methods.

\subsection{HPLC columns}

Table 2 presents values of chromatographic performance parameters for HPLC columns prepared by microwave irradiation. The silica was not previously dried, because the water sorbed on it contributes to fast microwave heating. The results indicate that microwave irradiation produces an improvement in the efficiency of the stationary phase and an immobilization of the polymer on the support. The increment in the values of $\% \mathrm{C}$ obtained with immobilization, as well as the decrease of the asymmetry factor, are indicative of good coverage of the chromatographic support by PMOS through microwave radiation. The parameters were obtained for a test mixture containing acetone, benzonitrile, benzene, toluene and naphthalene.

Chromatographic separations using columns immobilized by microwave irradiation were utilized to investigate fortified human urine samples to test the applicability of the described analytical procedure. A good separation of the analytes was obtained from spiked urine samples, when compared with a blank sample. Representative chromatograms are shown in Fig. 1.

\subsection{Method validation}

The linear regression parameters with correlation 
Table 3

Calibration curve and linearity for the herbicides

\begin{tabular}{|c|c|c|c|c|}
\hline \multirow[t]{2}{*}{ Herbicide } & \multicolumn{3}{|c|}{ Calibration curve $^{\mathrm{a}}$} & \multirow{2}{*}{$\begin{array}{l}\text { Linear interval } \\
(\mu \mathrm{g} / 1)\end{array}$} \\
\hline & $a$ & $b$ & $r$ & \\
\hline Diuro & 308.5 & 52.3 & 0.9998 & $40-1000$ \\
\hline Linuron & 13.7 & 45.5 & 0.9999 & $60-1500$ \\
\hline
\end{tabular}

${ }^{\mathrm{a}} y=a+b x, a=$ linear coefficient, $b=$ angular coefficient, $r=$ correlation coefficient.
Table 5

Limits of detection (LOD) and quantitation (LOQ) for the herbicides in matrix matched standards $(n=3)$

\begin{tabular}{lllll}
\hline Herbicide & $\begin{array}{l}\text { LOD } \\
(\mu \mathrm{g} / 1)\end{array}$ & $\begin{array}{l}\mathrm{LOQ} \\
(\mu \mathrm{g} / 1)\end{array}$ & $\begin{array}{l}\mathrm{LOD}^{\mathrm{a}} \\
(\mu \mathrm{g} / 1)\end{array}$ & $\begin{array}{l}\mathrm{LOQ}^{\mathrm{a}} \\
(\mu \mathrm{g} / 1)\end{array}$ \\
\hline Diuron & 14 & 40 & 2.8 & 8.0 \\
Linuron & 22 & 60 & 4.5 & 12 \\
\hline
\end{tabular}

${ }^{\mathrm{a}}$ LOD and LOQ after 5 -fold preconcentration; $n=3$ for all measurements.

Table 4

Precision (intra and inter-assay) and recovery for the SPE-HPLC determination of herbicides

\begin{tabular}{lccll}
\hline Herbicide & $\begin{array}{l}\text { Addition } \\
(\mu \mathrm{g} / \mathrm{l})\end{array}$ & $\begin{array}{l}\text { Recovery } \\
(\%)\end{array}$ & $\begin{array}{l}\text { Intra-assay } \\
\text { precision }(n=3) \\
\text { RSD }(\%)\end{array}$ & $\begin{array}{l}\text { Inter-assay } \\
\text { precision }(3 \text { days }) \\
\text { RSD }(\%)\end{array}$ \\
\hline Diuron & 40 & 95 & 1.8 & 1.6 \\
& 80 & 99 & 0.38 & 1.4 \\
Linuron & 103 & 85 & 1.5 & 1.0 \\
& 60 & 98 & 0.78 & 0.37 \\
\hline
\end{tabular}

$n$, number of replicates.

coefficients ( $r$ ) and parameters of the calibration curves constructed for detection of the herbicide at $254 \mathrm{~nm}$ are presented in Table 3.

Table 4 shows the recovery and the intra- and inter-assay precisions of the method. Recoveries were obtained by triplicate analysis of urine spiked with each compound at three levels of fortification for each herbicide.

The average results obtained for herbicide recoveries (Table 4) are very good, 60-10\% below $100 \mu \mathrm{g} / 1$ and $80-100 \%$ above $100 \mu \mathrm{g} / 1$, recoveries which are considered acceptable [22]. The results of the intra- and inter-assay runs show very good precision, with RSD values between 0.4 and $1.8 \%$, since for biological samples a RSD up to $15 \%$ is acceptable [22,26].

The results of LOD and LOQ, before and after preconcentration, are presented in Table 5. All these results are for analysis of urine.

\section{Conclusions}

The results presented in this paper show that a valid, precise, and specific method using laboratory prepared SPE and HPLC phases was developed for determination of diuron and linuron compounds in urine, with recoveries, precisions and limits of detection and quantification (Tables 4 and 5) in agreement with the values suggested in the literature.

Fast, easy and effective procedures to obtain silica-based $\mathrm{C}_{18}$-type sorbents for use in SPE and $\mathrm{C}_{8}$-type reversed stationary phases for HPLC applications are described. Good recoveries were obtained with SPE sorbents prepared by thermal immobilization of PMODS on silica (Table 4), which can be attributed to PMODS chain crosslinking, giving an extraction phase with excellent retention for these pesticides. The PMOS immobilized on silica by microwave irradiation results in high efficiency HPLC columns (Table 2) with good separation of the herbicides (Fig. 1). The main advantages of the procedures to obtain new SPE and HPLC materials are good performance, lower cost, simplicity and reduction of toxic residues.

\section{Acknowledgements}

The authors acknowledge financial support and 
fellowships from the Fundação de Amparo à Pesquisa do Estado de São Paulo (FAPESP), Conselho Nacional de Desenvolvimento Científico e Tecnológico $(\mathrm{CNPq})$ and travel support from the Fundo de Apoio ao Ensino e a Pesquisa (FAEP) of UNICAMP. The authors also thank C.H. Collins for helpful discussions and suggestions.

\section{References}

[1] R.H. Hill, D.B. Shealy, S.L. Head, C.C. Williams, S.L. Bailey, M. Gregg, S.E. Baker, L.L. Needham, J. Anal. Toxicol. 19 (1995) 323.

[2] M.D. Beeson, W.J. Driskell, D.B. Barr, Anal. Chem. 71 (1999) 3526

[3] M. van Boven, L. Laruelle, P. Daenens, J. Anal. Toxicol. 14 (1990) 231.

[4] E.R. Verheij, J. van der Greef, G.F. La Vos, W. van der Pol, W.M.A. Niessen, J. Anal. Toxicol. 13 (1989) 8.

[5] K. Wittke, H. Hajimiragha, L. Dunemann, J. Begerow, J. Chromatog. B 755 (2001) 215.

[6] S.C.N. Queiroz, C.H. Collins, I.C.S.F. Jardim, Quim. Nova 24 (2001) 68.

[7] E.M. Lores, F.C. Meekins, R.F. Moseman, J. Chromatogr. 188 (1980) 412.

[8] L.F.C. Melo, I.C.S.F. Jardim, J. Chromatogr. A 845 (1999) 423.

[9] L.F.C. Melo, C.H. Collins, K.E. Collins, I.C.S.F. Jardim, J. Chromatogr. A 869 (2000) 129.
[10] R.B. Silva, C.H. Collins, J. Chromatogr. A 845 (1999) 417.

[11] I.C.S.F. Jardim, K.E. Collins, T.A. Anazawa, J. Chromatogr. A 849 (1999) 299.

[12] S. Bachmann, L.F.C. Melo, R.B. Silva, T.A. Anazawa, I.C.S.F. Jardim, K.E. Collins, C.H. Collins, K. Albert, Chem. Mater. 13 (2001) 1874.

[13] E. Tonhi, S. Bachmann, K. Albert, I.C.S.F. Jardim, K.E. Collins, C.H. Collins, J. Chromatogr. A 948 (2002) 97.

[14] E. Tonhi, K.E. Collins, C.H. Collins, J. Chromatogr. A 948 (2002) 109.

[15] E. Tonhi, K.E. Collins, I.C.S.F. Jardim, C.H. Collins, Quim. Nova 25 (2002) 616.

[16] S.C.N. Queiroz, L.F.C. Melo, I.C.S.F. Jardim, J. Chromatogr. A 948 (2002) 171.

[17] H.M. Kingston, L.B. Jessie, in: Introduction to Microwave Sample Preparation (ACS Professional Reference Book), Vol. 263, American Chemical Society, Washington, DC, 1998.

[18] S.L. Cresswell, S.J. Haswell, J. Chem. Educ. 78 (2001) 900.

[19] A. Zlotorzynski, Crit. Rev. Anal. Chem. 25 (1995) 43.

[20] R. Causon, J. Chromatogr. B 689 (1997) 175.

[21] K.E. Collins, B.C. Franchon, I.C.S.F. Jardim, E. Radovanovic, M.C. Gonçalves, LC·GC 18 (2000) 106.

[22] D.R. Jenke, Instr. Sci. Technol. 26 (1998) 1.

[23] I. Krull, M. Swartz, LC·GC 15 (1997) 534.

[24] A.A.M. Chasin, E.S. Nascimento, L.M.R. Neto, M.E.P.B. Siqueira, M.H. Andraus, M.C. Salvador, N.A.G. Fernícola, R. Gorni, S. Salcedo, Rev. Bras. Toxicol. 11 (1998) 1.

[25] G.W. Peng, W.L. Chiou, J. Chromatogr. 531 (1990) 3.

[26] A.A.M. Chasin, M. Chasin, M.C. Salvador, Rev. Farm. Bioquim. 30 (1994) 49. 